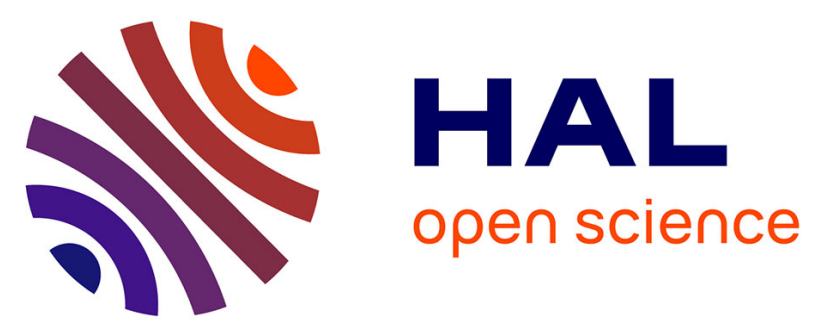

\title{
TDAB-induced DNA plasmid condensation on the surface of a reconstructed boron doped silicon substrate
} Antoine Mougin, Valéry G. Babak, Frank Palmino, Eric Bêche, Francis Baros, Darel J. Hunting, Léon Sanche, Michel Fromm

\section{- To cite this version:}

Antoine Mougin, Valéry G. Babak, Frank Palmino, Eric Bêche, Francis Baros, et al.. TDAB-induced DNA plasmid condensation on the surface of a reconstructed boron doped silicon substrate. Surface Science: A Journal Devoted to the Physics and Chemistry of Interfaces, 2008, 602 (1), pp.142-150. 10.1016/j.susc.2007.09.058 . hal-00516052

\section{HAL Id: hal-00516052 \\ https://hal.science/hal-00516052}

Submitted on 7 Oct 2021

HAL is a multi-disciplinary open access archive for the deposit and dissemination of scientific research documents, whether they are published or not. The documents may come from teaching and research institutions in France or abroad, or from public or private research centers.
L'archive ouverte pluridisciplinaire HAL, est destinée au dépôt et à la diffusion de documents scientifiques de niveau recherche, publiés ou non, émanant des établissements d'enseignement et de recherche français ou étrangers, des laboratoires publics ou privés. 


\title{
TDAB-induced DNA plasmid condensation on the surface of a reconstructed boron doped silicon substrate
}

\author{
Antoine Mougin a,b, Valéry G. Babak ${ }^{\mathrm{c}}$, Frank Palmino ${ }^{\mathrm{d}}$, Eric Bêche ${ }^{\mathrm{e}}$, Francis Baros ${ }^{\mathrm{f}}$, \\ Darel J. Hunting ${ }^{\mathrm{b}}$, Léon Sanche ${ }^{\mathrm{b}}$, Michel Fromm ${ }^{\mathrm{a}, *}$ \\ a $L M N-A C, U M R$ CEA E4, Université de Franche-Comté, 16 route de Gray, 25030 Besançon, France \\ b Centre for Research in Radiooncology, Faculté de Médecine, Université de Sherbrooke, Sherbrooke, QC, Canada J1H 5 N4 \\ c INEOS RAS, 28 Vavilova, Moscow 117813, Russian Federation \\ d FEMTO-STIDpt LPMO, UMR CNRS 6174, BP 71427, 25211 Montbéliard Cedex, France \\ e PROMES, UMR CNRS 8521, BP 5 Odeillo, 66125 Font Romeu Cedex, France \\ ${ }^{\mathrm{f}}$ UMR CNRS 7630/INPL, ENSIC-DCPR, 1 rue Grandville, 54001 Nancy Cedex, France
}

Our study aims at a better control and understanding of the transfer of a complex [DNA supercoiled plasmid - dodecyltrimethylammonium surfactant] layer from a liquid-vapour water interface onto a silicon surface without any additional cross-linker. The production of the complexed layer and its transfer from the aqueous subphase to the substrate is achieved with a Langmuir-Blodgett device. The substrate consists of a reconstructed boron doped silicon substrate with a nanometer-scale roughness. Using X-ray photoelectron spectroscopy and atomic force microscopy measurements, it is shown that the DNA complexes are stretched in a disorderly manner throughout a 2-4 nm high net-like structure. This architecture is composed of tilted cationic surfactant molecules bound electrostatically to DNA, which exhibits a characteristic network arrangement with a measured average fiber diameter of about $45 \pm 15 \mathrm{~nm}$ covering the entire surface. The mechanism of transfer of this layer onto the planar surface of the semi-conductor and the parameters of the process are analysed and illustrated by atomic force microscopy snapshots. The molecular layer exhibits the typical characteristics of a spinodal decomposition pattern or dewetting features. Plasmid molecules appear like long flattened fibers covering the surface, forming holes of various shapes and areas. The cluster-cluster aggregation of the complex structure gets very much denser on the substrate edge. The supercoiled DNA plasmids undergo conformational changes and a high degree of condensation and aggregation is observed. Perspectives and potential applications are considered.

Keywords: Nanopatterning; Atomic force microscopy; Langmuir/Blodgett/Kuhn assemblies; DNA surfactants

\section{Introduction}

This work aims at developing a method for depositing onto a planar conductive surface a well-characterized monolayer of self-assembled desoxyribonucleic acid (DNA) supercoiled plasmids bound to cationic surfactant molecules (tetradecyltrimethylammonium bromide, TDAB

\footnotetext{
* Corresponding author. Tel.: +33 3816665 60; fax: +33 381666522

E-mail address: michel.fromm@univ-fcomte.fr (M. Fromm).
}

or $\left.\mathrm{C}_{14} \mathrm{TAB}\right)$. In many studies, different types of cross-linker or modified surfaces were used to immobilize DNA onto a substrate [1-3], or to chemically bind oligonucleotides onto a given substrate. Additionally, in recent years, the adsorption/desorption mechanisms of various organic molecules at the silica-aqueous surface have been investigated [4]. Adsorption of biomolecules on silica surfaces as well as competition between surfactants and polymers during the adsorption process is also of current interest. Moreover, many contributions have focused on the formation of 
complexes involving DNA. These systems have been extensively studied even though the mechanism of formation is not completely understood [5]. In such experiments, the DNA layers must be characterized, in particular it is essential to understand the underlying self-assembly processes resulting in the formation of the supramolecular structures under investigation. Trying to understand the effect of $2 \mathrm{D}$ nanoscale supramolecular organization and patterning when mixing DNA with a cationic amphiphile monolayer in complex Langmuir-Blodgett (LB) films is a more recent topic. Learning how to control such biomolecular assembly processes and application of these principles to fabricate new functional nanostructures and nanostructured materials can be an effective approach in nanoscale science, advanced materials research and molecular nanotechnology.

With TAX standing for "trimethylammonium halide" and $n$ for the number of carbon atoms of an aliphatic chain, $\mathrm{C}_{n}$ TAX $(n=12-16$ and $\mathrm{X}=\mathrm{Br}, \mathrm{Cl}$ or $\mathrm{F})$ surfactants, as well as their complexes with polyanions are frequently used as model systems. For example, with [surfactant $] / \mathrm{CMC}<0.1$, where $\mathrm{CMC}$ stands for the critical micelisation concentration, Cardenas et al. [6] have shown that the stability of mixed $\mathrm{C}_{n} \mathrm{TAX} / \mathrm{DNA}$ layers adsorbed onto hydrophobized silica surfaces; p-type boron doped and oxidized silicon wafers, silanized with dimethyloctylchlorosilane, largely depends on the cationic surfactant length $(n)$ in presence of $10 \mathrm{mM} \mathrm{NaX} . \mathrm{C}_{12} \mathrm{TAB}$ (DTAB) was found to be the least stable complex and to adsorb close to the point of phase separation. Interestingly, these authors did mention that one would expect the complete removal of the cationic surfactant from the mixed layer by continuous rinsing with $10 \mathrm{mM} \mathrm{NaX}$ solution. It thus seemed interesting to focus our attention on TDAB $\left(\mathrm{C}_{14} \mathrm{TAB}\right.$ or tetradecyltrimethylammonium bromide) due to its weak to intermediate stability when complexed with DNA. Therefore, deposition of TDAB/DNA complexes is here realized by means of the weak intermolecular forces between the formed complexes and the surface atoms. In this case, structured monolayers in the dilute regime, far under the $\mathrm{CMC}$, are produced without any particular treatment except for a prior surface reconstruction of the boron doped silicon surface.

The Langmuir-Blodgett device is a powerful tool to electrostatically assemble different ionic molecules and build well controlled ultrathin organic films [7]. In order to retain and increase the concentration of water soluble DNA macroanions onto the air-water interface, one forms electrostatically and hydrophobically stabilized complexes between the charged DNA macroanions and positively charged cationic lipids, the so-called surfactant-polyelectrolyte complexes (SPECs). The cooperative interactions between both water soluble DNA and surfactant molecules at the air-water interface makes the SPECs practically water insoluble and undesorbable from the interface into the bulk of the aqueous solution. The TDA ${ }^{+}$amphiphilic ions, bound to DNA by multiple electrostatic contacts, produce the hydrophobisation of DNA macroanions by attaching long hydrophobic alkyl chains to the macromolecular backbone and consequently highly increase the adsorption activity of these SPECs. As received or cleaned silicon and boron doped silicon surfaces are indeed characterized by a surface energy of the order of $40-50 \mathrm{~mJ} \mathrm{~m}^{-2}$ with a $\delta_{\mathrm{sw}}^{-} \gg \delta_{\mathrm{sw}}^{+}(\delta$ stands for the polar components of the surface energy). Therefore, for the mixed DNA-cationic surfactant complex, adsorption will occur and increase only when the repulsion between the DNA macromolecule and the surface is sufficiently decreased due to the cationic surfactant-DNA interaction.

It is known that surfactant-polyelectrolyte complexes form organized structures at the air-water interface [8]. It has for example been shown [9] that DNA forms electrostatically and hydrophobically stabilized complexes with amphiphilic molecules like CPB (cetylpiridinium bromide) in the Langmuir films, and that these complexes are separated in macroscopic aggregates at the water-air interface. Dai et al. produced nanopatterned DNA films on a flat mica surface using the LB technique and an octadecylamine (ODA) surfactant [10]. With a 3000 base pair (bp) Calf Thymus DNA they obtained original structures, called "fractal-like structure", which are characterized by the formation of dendrites in the ODA/DNA coating. The coverage and therefore the compaction of the ODA/DNA complexes were found to vary with the pressure applied per unit area of the LB trough. In the present LB experiments, we use $3197 \mathrm{bp}$ supercoiled plasmids complexed with TDAB in order to build a molecular layer on a reconstructed boron doped silicon surface with a well-defined flatness. We analyse the TDAB/DNA complexes formed on the boron doped silicon surface at the very beginning of the specific TDAB/DNA phase transition. Compared to higher order homologues, TDAB has a lowest stability when associated with DNA in water [6]. Furthermore, the supercoiled plasmids are characterized by a high flexibility [11] and their particular topology can undergo considerable transformation. One possible pathway is relaxation from its plectonemic form to its circular form. This relaxation can be either irreversible or reversible and can be driven by external perturbations such as a single strand break (irreversible relaxation) or even changes in the ionic-strength, $\mathrm{pH}$ or temperature of the surrounding medium (reversible relaxation). With the exception of a single strand break, the other conditions listed above can result in a reversible opening of portions of the primary DNA helix to relieve the supercoiling stress. Condensation is another pathway generally mediated by multicharged cations. Condensation occurs in several possible forms: rectangular block-like, rods, toroids, flower-like [12] with linear double-strands. When dealing with circular plasmid condensation, the following forms have been observed: circular, thick flattened, compact, toroidal and rod-like [13]. We report here the formation of condensed rods assembled in an interlaced monolayer where complexation is achieved with a monovalent cationic surfactant. 


\section{Materials and methods}

\subsection{Materials}

Supercoiled DNA (Pgem 3ZF(-), 3197 bps, ca. $1.9 \times 10^{6}$ amu per plasmid) was extracted from Escherichia coli JM109, purified with HiSpeed Plasmid Maxi Kit (Qiagen) and resuspended in ultrapure water. The DNA concentration was measured spectrophotometrically by its absorbance using the specific extinction coefficient $\varepsilon=1$, $31 \times 10^{4} \mathrm{~mol}^{-1} \mathrm{~cm}^{-1}$ at $260 \mathrm{~nm}$; the absorbance at $320 \mathrm{~nm}$ was negligible indicating the absence of protein contamination [14]. The final DNA solution was adjusted to $0.075 \mathrm{~g} /$ L. Following purification, less than $8 \% \pm 1$ of the DNA population are in the circular conformation according to our measurements based on $1 \%$ agarose gel electrophoresis in TAE buffer at $6.7 \mathrm{~V} \mathrm{~cm}^{-1}$ for $7 \mathrm{~min}$ and $5.0 \mathrm{~V} \mathrm{~cm}^{-1}$ for $68 \mathrm{~min}$. Both the gel and DNA were prestained with SYBR-Green 1 (Molecular Probes) $(1 \times$ for gel and $20 \times$ for DNA, respectively) and then analyses were made by fluorescence [15]. Amphiphilic molecules of tetradecylmethyl ammonium bromide (TDAB) were supplied by Aldrich with a guaranteed purity of $98 \%$; they were used without further purification. All aqueous solutions were prepared with ultrapure water having a resistivity of $18.2 \mathrm{M} \Omega \mathrm{cm}$.

\subsection{Surface preparation}

Silicon samples are prepared in an UHV chamber. The boron doped $\operatorname{Si}(111)$ substrate $\left(10^{-3} \Omega \mathrm{cm}\right.$ resistivity) is carefully outgased and cleaned in situ by a series of rapid heatings to $1150{ }^{\circ} \mathrm{C}$ under a pressure less than $10^{-9}$ mbar. Afterwards, a thermal process (several hours at $750{ }^{\circ} \mathrm{C}$ ) activates the boron segregation at the surface and a boron atom concentration of $1 / 3$ monolayer (ML) is obtained (one ML is referred to as the $\mathrm{Si}(111)$ atomic density with $7.8310^{14}$ atom $\left.\mathrm{cm}^{2}\right)$. The surface exhibits an ideal surface boron $(\sqrt{ } 3 \times \sqrt{ } 3) \mathrm{R} 30^{\circ}$ reconstruction. This structure is explained by the presence of a boron atom, in the third layer, just underneath the $\mathrm{Si}$ adatom. The boron atom, substituted for a silicon atom induces a charge transfer from the Si adatom to the boron atom, which partially passivates the surface [23]. We obtain in this case a silicon surface with empty dangling bonds.

\subsection{Langmuir-Blodgett films}

The monolayers of TDAB/DNA complexes were formed based on a novel method consisting of spreading the aqueous solution of DNA with a microsyringe on the aqueous subphase containing the TDAB solution. A DNA concentration of $4 \times 10^{-8} \mathrm{~mol} / \mathrm{L}$ and a TDAB concentration of $10^{-5} \mathrm{~mol} / \mathrm{L}$ were chosen to ensure the insolubility of the electrostatic complexes. This method allowed us to avoid the undesirable contact of the DNA with organic solvents currently used in classical spreading of polymers bound to soluble surfactants on the aqueous subphase.
The films were prepared in a trough having a carboncoated surface and a moving barrier. Compression was initiated $10 \mathrm{~min}$ after spreading the amphiphilic molecules, which allowed a TDAB/DNA layer to be formed in the aqueous subphase. The $\pi-A$ isotherms were measured at a constant barrier speed of $7.5 \mathrm{~cm}^{2} \mathrm{~min}^{-1}$ by a computercontrolled KSV-1100 film balance system (KSV Instruments, Helsinki, Finland) and the surface pressure by a platinum Wilhermy balance of $39.3 \mathrm{~mm}$ perimeter. The maximum surface area was $242 \mathrm{~cm}^{2}$ and the subphase was maintained at a temperature of $22{ }^{\circ} \mathrm{C}$. The LB films were formed after previous compression of the TDAB/ DNA complex layers under selected constant values. These layers were transferred onto reconstructed boron doped silicon using the vertical lift technique at a dipping speed of $5 \mathrm{~mm} \mathrm{~min}{ }^{-1}$ according to the specific isotherm of our system.

\subsection{Characterization by AFM and XPS}

AFM images were obtained with a Nanoscope IIIa (Digital Instruments Inc.). V-shaped silicon nitride cantilevers at resonant frequencies of $300 \mathrm{kHz}$ in the tapping mode to record height images of the surface at atmospheric pressure. XPS analysis was performed using a SIA Riber Cameca UHV device operating at a pressure of $10^{-8}$ Torr. The photoelectron emission spectra were recorded using an $\mathrm{MgK} \alpha \quad(h v=1253.6 \mathrm{eV})$ non-monochromatized source $(350 \mathrm{~W})$. The angle between the X-ray direction and the emitted electron direction was $60^{\circ}$. The area analysed was about $25 \mathrm{~mm}^{2}$. The kinetic energy of the photoelectrons was measured with a two stage Riber Cameca MAC 2 spectroscopic spectrometer at an analyser resolution of $1 \mathrm{eV}$. The spectrometer energy scale was calibrated using the $\mathrm{Au} 4 \mathrm{f} 2(83.9 \pm 0.1 \mathrm{eV})$ and $\mathrm{Cu} 2 \mathrm{p} 2(932.8 \pm 0.1 \mathrm{eV})$ photoelectron lines with respect to the Fermi level. XPS and XAES spectra were recorded in direct $N(E)$. The background signal was removed using the Shirley method [16]. The surface atomic concentrations were determined from photoelectron peak areas $(\mathrm{C} 1 \mathrm{~s}, \mathrm{O} 1 \mathrm{~s}, \mathrm{~N} 1 \mathrm{~s})$ using the atomic sensitivity factors reported by Scofield [17] and taking into account the transmission function of the analyser. The binding energy scale was established by referencing the $\mathrm{O} 2 \mathrm{~s}$ value $(25 \mathrm{eV})$ and the $\mathrm{C} 1 \mathrm{~s}$ value of carbon $(285 \mathrm{eV}$, useful international standard in polymer analysis by XPS) [18]. The C 1s and O 1s photoelectron peaks were analysed by Gaussian/Lorentzian peak fitting. The full width at half maximum (FWHM) and the positions of the components were compared to those observed for our polymer reference samples [19] to insure that the acquisition times did not cause significant damage.

\section{Results and discussion}

The ratio of positive charges due to TDAB cations $\left(250 \mathrm{~mL}, 10^{-5} \mathrm{M}\right)$ over the total negative electrical charges due to the DNA $\left(27 \mu \mathrm{L}, 4 \times 10^{-8} \mathrm{M}\right)$ smeared over the 
Langmuir film is a key parameter in our experiments. With TDAB amphiphilic molecules in aqueous solution, at room temperature $\left(25^{\circ} \mathrm{C}\right)$, the $\mathrm{CMC}$ is known to be $\sim 3.5 \mathrm{mM}$ [20]; we used a $[\mathrm{TDAB}]=10^{-2} \mathrm{mM} \ll \mathrm{CMC}$. Apart from bromide $\mathrm{TDA}^{+}$counterions, other ions in the drop were the DNA counterions (mostly $\mathrm{Na}^{+}$and $\mathrm{H}_{3} \mathrm{O}^{+}$); no other ions were added during the process. Based on a Langmuir adsorption isotherm

$\Gamma\left(C_{\mathrm{s}}\right)=\Gamma_{\max }\left(\frac{b C_{\mathrm{s}}}{1+b C_{\mathrm{s}}}\right)$

with $\Gamma_{\max }=a / R T, a=0.011 \mathrm{~J} / \mathrm{m}^{2}$ and $b=1.67 \mathrm{~L} / \mathrm{mol}$, the equilibrium adsorption value, $\Gamma\left(C_{\mathrm{s}}\right)$, corresponding to the surfactant concentration $C_{\mathrm{s}}=10^{-5} \mathrm{~mol} / \mathrm{L}$ was estimated to be $\Gamma=7 \times 10^{-10} \mathrm{~mol} / \mathrm{m}^{2}$. Thus, the surface density of positively charged trimethylammonium ions is equal to $n^{+}=7 \times 10^{-10} \mathrm{~mol} / \mathrm{m}^{2}$. The quantity of negative charges $N^{-}$due to DNA is estimated to be $N^{-}=2 \times 3197 \times$ $C_{\mathrm{DNA}} \times V_{\mathrm{DNA}}=7.10^{-9} \mathrm{~mol}$. We obtain the value $n^{-}=N^{-} / A_{0}=3 \times 10^{-6} \mathrm{~mol} / \mathrm{m}^{2}$ for the upper limit of the surface density, $n^{-}$, of the phosphate groups at the surface of the aqueous solution with the initial area $A_{0}=242 \mathrm{~cm}^{2}$. On the other hand, considering all charges, the total number of negative charges from DNA is $7 \times 10^{-9} \mathrm{~mol}$ while the total positive charges from $\mathrm{TDA}^{+}$is $2.5 \times 10^{-6} \mathrm{~mol}$, which is three orders of magnitude higher, so that most of the solubilized plasmids can be partially or totally neutralized by the $\mathrm{TDA}^{+}$and therefore behave as hydrophobic species. Compression was initiated $10 \mathrm{~min}$ after smearing the DNA solution on the macroscopic aggregates of the amphiphilic molecules that form the superficial film. During compression of the barrier, the DNA aggregates due to electrostatical forces until it starts mixing with the subphase layer, as shown by the increase in surface pressure in the $\pi-A$ isotherms (Fig. 1). In this compression curve, the shoulder at $21 \mathrm{mN} / \mathrm{m}$ indicates a transition to the solid phase regime of the LB film. The electrostatic interaction between DNA and cationic amphiphilic molecules is responsible for the observed surface rigidity. The method used in this work consists in the spreading of a DNA solution droplet onto the Langmuir layer formed by the TDAB molecules. This method was found to be the most reliable as well as the most economic. An alternative often used method is the following: the DNA is first put into solution, then incubated for the time necessary for the complex to be formed by means of diffusion from the bulk to the interface where the TDAB layer electrostatically attracts the DNA polyanions.

With this last method, the amount of DNA to be used is very high and the incubation time must be greater than half an hour under our conditions. Our spreading method requires a $27 \mu \mathrm{L}$ droplet of DNA solution and an incubation time of $10 \mathrm{~min}$. Within our experimental conditions, we are not capable of determining exactly the amount of DNA that passes from the interface into the solution. Conventionally, in the LB experiments, the assumption can be made that the total number of DNA molecules introduced

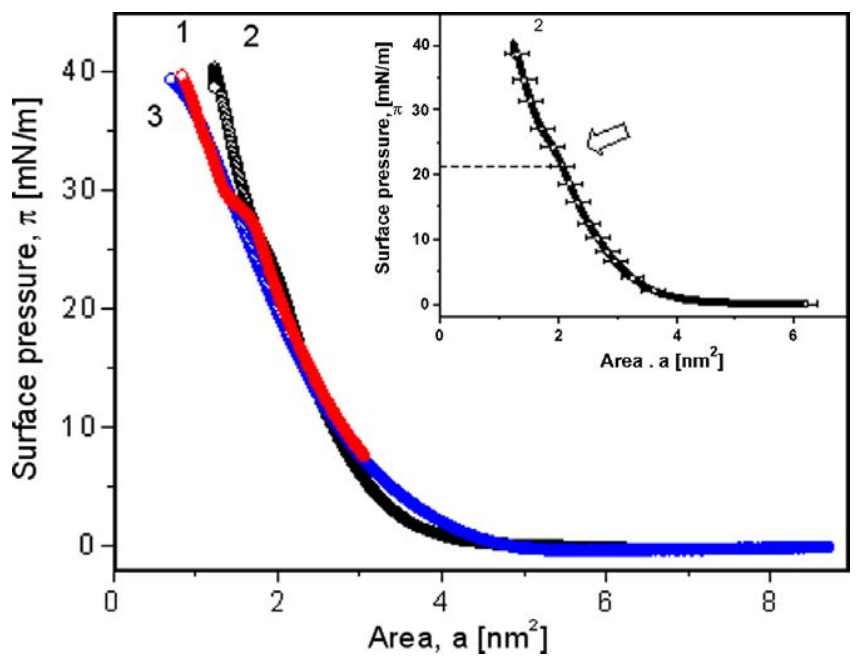

Fig. 1. Isotherm of DNA (Pgem $3 \mathrm{ZF}(-)$, $3197 \mathrm{bps}$, ca. $1.9 \times 10^{6}$ amu per plasmid, $\left.4 \times 10^{-8} \mathrm{~mol} / \mathrm{L}\right)$ and TDAB $\left(10^{-5} \mathrm{~mol} / \mathrm{L}\right)$ at $22^{\circ} \mathrm{C}$. Curves 1 and 2 correspond to the spreading method and curve 3 corresponds to the adsorption of the DNA from the bulk to the interface ( 30 min incubation). These three curves have been normalized assuming that the initial number of DNA macromolecules added in the bath fully react with the TDAB molecules forming the Langmuir layer. The inset shows the curve corresponding to the experiments described in this paper (spreading of a $27 \mu \mathrm{L}$ drop of the DNA solution), the error bars correspond to the maximum deviations observed among all our LB experiments. The arrow points on the shoulder produced by the transition to the solid phase regime of the LB film.

remains the same, i.e. we suppose that none of these molecules escape into the bulk. By this way, we normalize the $\pi$ $A$ isotherms and express the area in function of an average value (within our conditions, $a_{0}=5.74 \mathrm{~nm}^{2}$ ) equal to the entire area of the trough divided by the total number of phosphate groups that will electrostatically react with the $\mathrm{TDA}^{+}$cations.

The isotherm shows that TDAB on DNA in the subphase exhibits an expansion which is evidenced by the compaction of DNA molecules. During this step, an electrostatic mixing occurs at the surface tending to assemble $\mathrm{TDA}^{+}$cations with DNA soluble polyanions forming the TDAB/DNA complex layer at the liquid-vapour interface. As soon as compaction at $21 \mathrm{mN} \mathrm{m}^{-1}$ (see arrow on Fig. 1) is achieved, the immersed boron doped silicon $(\mathrm{Si}(\mathrm{B}))$ plate is lifted. The resulting layer deposed on the $\mathrm{Si}(\mathrm{B})$ surface is analysed by of XPS and AFM.

AFM analyses are performed in the tapping mode on the center of the samples as well as on its borders. Fig. 2 shows a typical image of the TDAB/DNA structure observed on the sample surface after the vertical LB deposition was performed. On the top of this image, a scratch is visible which indicates the formation of a nanometer-scale supramolecular coating. The flatness of the surface at the nanometer-scale is also clearly illustrated when comparing the part of the surface that remains in contact with the air (the scratch) and the lower part of the figure where atomic terraces, specific for reconstructed boron doped silicon, are visible. In order to make this clearer, an image of a reconstructed $\mathrm{Si}(\mathrm{B})$ surface 


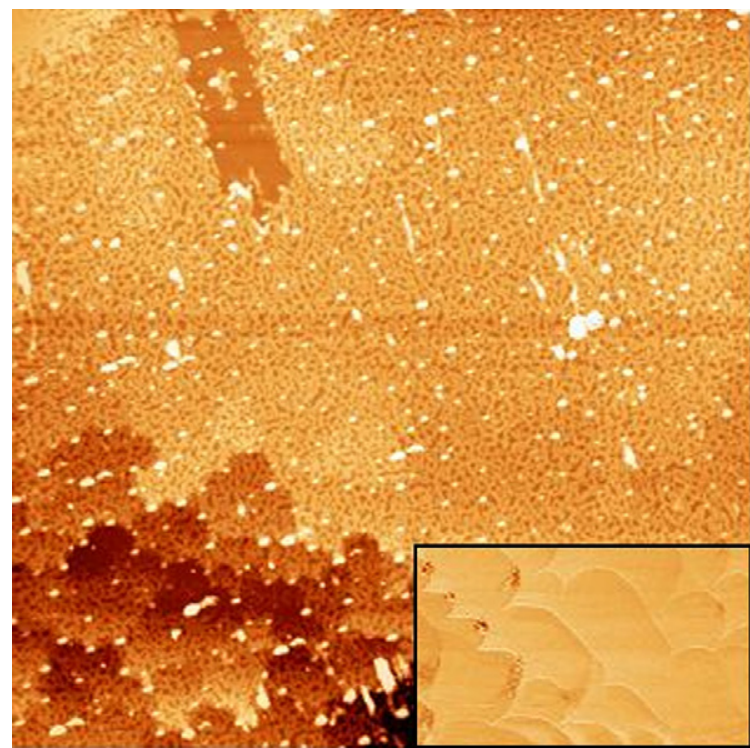

Fig. 2. AFM image (tapping mode) of the TDAB/DNA complex transferred onto the $\mathrm{Si}(\mathrm{B})$ surface. On the left lower portion of the observed field, atomic terraces covered by the complex molecular network are visible. The inset shows such terraces $(0.384 \mathrm{~nm}$ high $)$ imaged on a $\mathrm{Si}(\mathrm{B})$ sample before it was immersed in the LB trough. Atmospheric contaminants are disseminated over the layer and appear under the form of white grains. The observed area is $8 \times 8 \mu \mathrm{m}^{2}$.

obtained prior to the LB process is inseted at the bottom right of Fig. 2 to show the characteristic $0.384 \mathrm{~nm}$ high uncovered terraces (one bi-layer).

RMS measurements made over the observation fields indicate that the height of the TDAB/DNA structures ranges from 2 to $4 \mathrm{~nm}$. An average width of $45 \pm 15 \mathrm{~nm}$ for the fibers was measured from the different scanned fields. The height value is of the order of the doubledstranded DNA diameter of $2 \mathrm{~nm}$. This indicates that most of the clusters composed of TDAB electrostatically bounded to the DNA lie flat on the $\mathrm{Si}(\mathrm{B})$ surface, which might account for the surface strain driven structure of the layer. There is uncertainty in the determination of the mean width of the TDAB/DNA fibers due to limitations in the sharpness of the cantilever tip. As mentioned by Nie and McIntyre, the tip diameter can also be increased due to contamination [21]. In our case, the diameter of the tip of the cantilever is typically $d=10 \mathrm{~nm}$. As mentioned elsewhere [22], the overestimation in determining the fiber dimensions is approximately $\left(d^{2}+L^{2}\right)^{1 / 2}$.

The length of a $\mathrm{C}_{n} \mathrm{TAB}$ molecule in the all-trans conformation of the alkyl chain is given by Pauling [23]

$\ell\left(\mathrm{C}_{n} \mathrm{TAB}\right)=0.245\left(\frac{n}{2}-1\right)+r_{\mathrm{Me}}+r_{\mathrm{N}-\mathrm{Me}}$

With the van der Walls radii of the methyl $\left(r_{\mathrm{Me}}=0.20 \mathrm{~nm}\right)$ and trimethylammonium $\left(r_{\mathrm{N}-\mathrm{Me}}=0.35 \mathrm{~nm}\right)$ end groups, (2) yields $1.78 \mathrm{~nm}$. Thus, with a $2 \mathrm{~nm}$ diameter DNA double-strand, supercoiled circular plasmids condensed with TDAB molecules bound to each side, with a mean length of $1.78 \mathrm{~nm}$ in their zig-zag form, have an average size of
$5.5 \mathrm{~nm}$. Taking into account the plectonemic topology of the supercoiled plasmids, a mean fiber diameter of $\sim 20 \mathrm{~nm}$ is considered as a sound estimate of a twice-folded fiber diameter (see Fig. 3). This estimate of $20 \mathrm{~nm}$ leads to a $22 \mathrm{~nm}$ overestimation of the mean fiber diameter. To be consistent with the average measurement of $45 \pm 15 \mathrm{~nm}$, more than two folds per plasmid must be considered. Therefore, the most probable configuration of the TDAB/DNA complex is an arrangement of manifold interlacing plasmids sandwiched between TDAB molecules tilted toward the surface plane.

The plasmids are linked through hydrophobic bondings and form fibers. A different arrangement of the TDAB/ DNA complex near the edge of the sample exists owing to the higher density of the layer or surface coverage. Compaction can be attributed to the dipping of the sample at the edges which induces a short attraction of the compressed liquid surface owing to capillary forces as well as an elastic pulling force acting during the layer break-up. The characteristic height of that denser part of the molecular structure nevertheless appears to be lower than elsewhere on the sample; i.e., respectively $2-2.5 \mathrm{~nm}$ instead of 2-4 nm. In contrast, the average width of the fibers remains of the order of $45 \pm 15 \mathrm{~nm}$. A typical high-density TDAB/ DNA layer is presented in Fig. 5. On this Figure a very high level of compaction of the coating is achieved. Moreover, the TDAB/DNA coating exhibits a non-periodic ordered-like structure.

XPS analyses of the whole surface (Table 1) confirm the presence of DNA based on the signature of the phosphate $2 p$ photoelectron peak $(1.2 \%)$ which arises only from the DNA backbone. In addition, when compared with the atomic content of the uncovered $\mathrm{Si}(\mathrm{B})$ interface, the carbon composition increases notably after the putative TDAB/ DNA complex has been deposited. In addition, nitrogen is present $(3.4 \%)$ and a very low decrease in the oxygen composition is measured, all of which is consistent with the presence of DNA. The decrease in the oxygen content

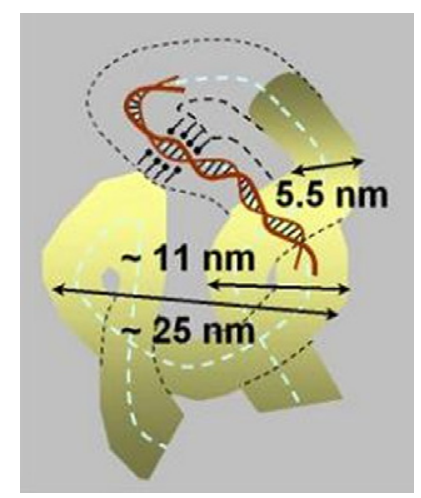

Fig. 3. Schematic view of a DNA supercoiled plasmid complexed with $\mathrm{TDA}^{+}$amphiphile ions. The width of a TDAB-DNA-TDAB structure in the plane of the surface is $\sim 5.5 \mathrm{~nm}$. Due to its supercoiled conformation, the DNA molecule complexed to TDAB has a width greater than $11 \mathrm{~nm}$; the addition of one more interweaving results in dimensions greater than $25 \mathrm{~nm}$ or more. 
Table 1

Results of XPS spectra analysis for $\mathrm{Si}(\mathrm{B})$ reconstruction and $\mathrm{Si}(\mathrm{B})$ with DTAB/DNA LB deposition

\begin{tabular}{llllllll}
\hline Type of sample & \multicolumn{7}{l}{ Atomic concentration (at.\% \pm 3$)$} \\
\cline { 2 - 8 } & C 1s & O 1s & Si 2p & B 1s & N 1s & P 2p & Br 3d \\
\hline SiB & 27 & 26 & 46 & 3 & 0 & 0 & 0 \\
SiB LB & 50 & 21 & 24 & 0 & 3 & 1 & 0 \\
\hline
\end{tabular}

when the layer covers the surface can easily be understood. XPS analyses of the uncovered surface of a $\mathrm{Si}(\mathrm{B})$ sample maintained in air show that oxygen is present at $25 \%$ due to the formation of superficial silicon oxides, mainly hydroxyl and etherial [4].

The atomic composition in oxygen measured on the sample covered with the TDAB/DNA molecular layer is somewhat less than $1 / 4(21 \%)$, which is consistent with the lower average oxygen composition of the DNA layer $(<15 \%$ for A, G, T, C bases of the DNA to which the oxygen composition of ribose and phosphate groups must be added). In addition, the plasmids are themselves complexed with the TDAB molecules, which lower the oxygen composition of the layer. The $\mathrm{O} 1 \mathrm{~s}$ core-level spectrum can be resolved into two components, with the exception of adenine and a possible small contribution of $\mathrm{O}-\mathrm{Si}$ bonds. A component located at $532.8 \mathrm{eV}$ corresponds principally to carbonyl oxygen atoms $(\mathrm{O}=\mathrm{C})$ characteristic of three of the DNA bases $[25,26]$. On the other hand, the $534.2 \mathrm{eV}$ component is mainly attributed to oxygen atoms $(\mathrm{C}-\mathrm{O}-\mathrm{C})$ related to the DNA backbone (deoxyribose).

The $\mathrm{P} 2 \mathrm{p}$ photoelectron peak is located at $133.2 \mathrm{eV}$. This peak position is attributed to $\mathrm{P}-\mathrm{O}$ bondings in $\mathrm{PO}_{3}$ and/or $\mathrm{PO}_{4}^{2-}[27-31]$. X-ray photoelectron spectroscopy analyses also show that boron in the subsurface substitutional sites is no longer detected when the complex layer covers the surface (Figs. 2, 4 and 5). The maximum occupation of boron in the substitution sites of silicon is obtained with our reconstruction procedure; boron is then located at the third layer starting from the adatoms. An extinction of the boron XPS signal signifies that the oxide layer and the deposited TDAB/DNA layer are larger than the mean free path of the B 1s photoelectrons ejected from the subsurface. It should be noted that the atomic composition $(\%)$ of silicon appears to be reduced by a factor 2 when the surface is covered by the complex. The mean free path of $2 p$ silicon photoelectrons in pure silicon can be calculated using the empirical relation proposed by Seah [32]. Under our conditions

$\lambda_{\mathrm{Si}}=\left(0.41 \mathrm{~nm}^{-1 / 2} \mathrm{eV}^{-1 / 2}\right) \times a_{\mathrm{Si}}^{1.5} \times E_{\mathrm{Si}}^{0.5}$

$a_{\mathrm{Si}}$ is the silicon atom size estimated from the silicon crystal density $\left(2.328 \mathrm{~g} \mathrm{~cm}^{-3}\right)$ and $E_{\mathrm{Si}}$ is the kinetic energy of the $2 \mathrm{p}$ Si photoelectron. With a $\mathrm{MgK} \alpha$ photon energy of $1254 \mathrm{eV}$, a spectrometer work function of $4 \mathrm{eV}$ and a $\mathrm{Si}$ binding energy of $100 \mathrm{eV}$, we find $\lambda \sim 2 \mathrm{~nm}$ in pure silicon. The B 1s binding energy is typically $188 \mathrm{eV}$ which yields, roughly the same $\lambda \sim 2 \mathrm{~nm}$ (1.97 instead of 1.88) in pure silicon. As a consequence, keeping in mind that (1) the initial boron atomic composition measured in the sample was only $2.6 \%$ (Table 1 ), and (2) boron atoms are located beneath the silicon surface $(0.384 \mathrm{~nm})$ under two silicon layers [33], this value is consistent with a TDAD/DNA coating of 2-4 nm; i.e., a coating sufficiently dense to screen most of the B 1s photoelectrons escaping from beneath the surface. The notable carbon composition observed on the analysed surfaces can be imputed to pollution by hydrocarbons emitted into the atmosphere by biogenic and anthropogenic sources [34]. When analysing the covered silicon boron doped substrate, the detection of nitrogen $(3 \%)$
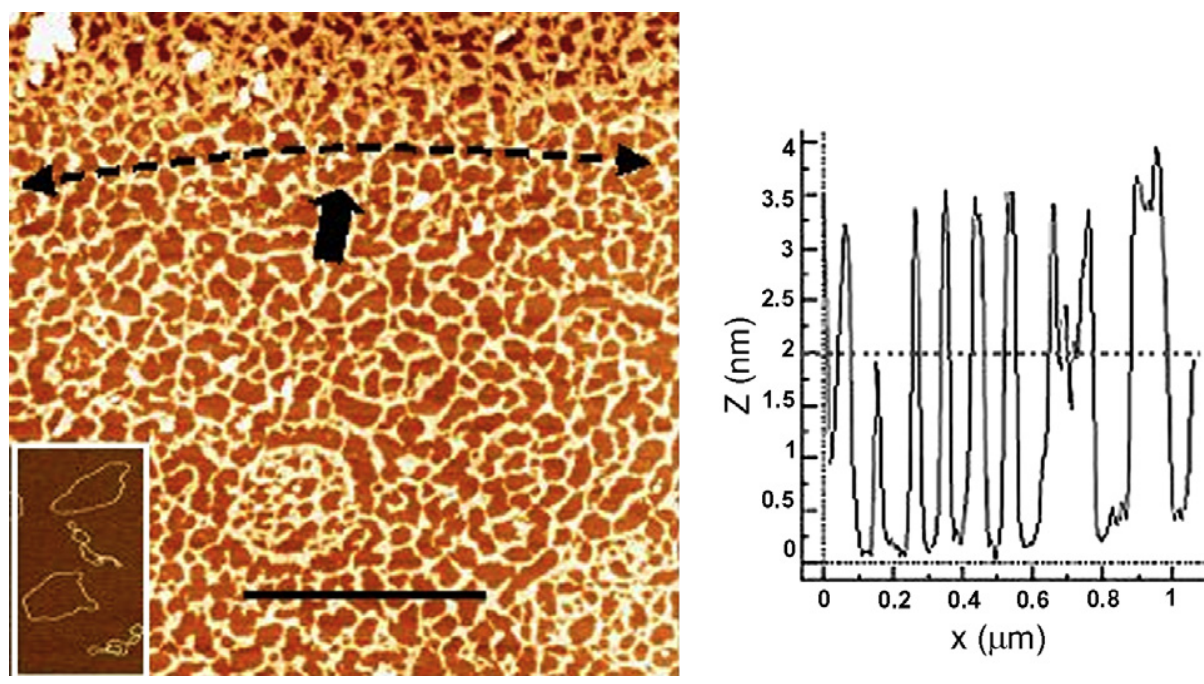

Fig. 4. Shown on the left is a $3 \times 3 \mu \mathrm{m}^{2}$ AFM image (tapping mode) of the TDAB/plasmid DNA network. The left inset shows the same plasmids in their supercoiled and circular form deposited onto mica, at the same magnification [24]. On the upper part of the AFM image (see arrow), a sinuous limit (the dashed line is to guide the eye) separates a denser layer from the rest of the coating. The mean width of the fibers is $45 \pm 15 \mathrm{~nm}$ and height is $2-4 \mathrm{~nm}$. The height distribution which appears on the right panel is measured along the full line on the AFM image. The horizontal dashed lines on the $Z(X)$ distribution account respectively for the substrate $(0 \mathrm{~nm})$ and for a naked double-stranded DNA molecule diameter $(2 \mathrm{~nm})$. 

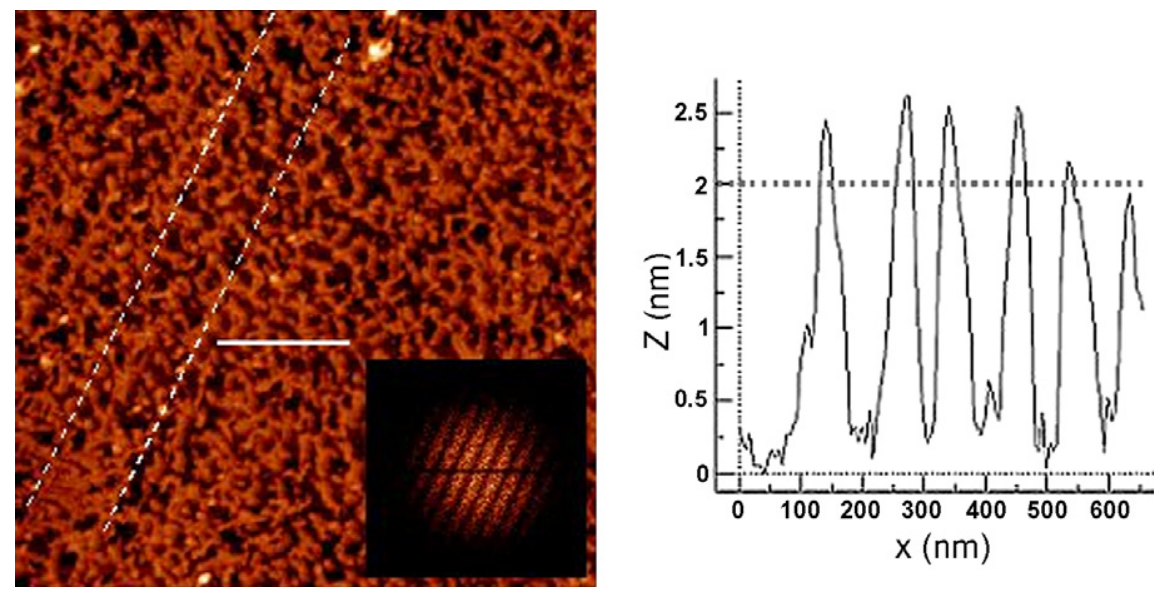

Fig. 5. AFM image (tapping mode) of the TDAB/DNA network observed at the vicinity of the leaving edge of the $\mathrm{Si}(\mathrm{B})$ plate. The observed area is $3 \times 3 \mu \mathrm{m}^{2}$. The surface coverage is much higher than on the remaining part of the sample. The compaction of the complex leads to a non-periodic orderedlike film structure (oblique dashed lines), which is confirmed by the Fourier Transform (inset). The height distribution on the right is measured along the full line that appears on the left image. The horizontal dashed lines on the $Z(X)$ distribution account respectively for the substrate $(0 \mathrm{~nm})$ and for the diameter of a naked double-stranded DNA molecule $(2 \mathrm{~nm})$.

corroborates well the presence of DNA and TDAB. Nitrogen is present both in the DNA bases (less than $8 \%$ per nucleotide) and in the TDAB molecule $(\sim 2 \%)$.

Bromide and sodium counterions were not detected by means of XPS analyses of the Blodgetted surface, indicating that most of these counterions remained in the liquid phase. Screening of the DNA negative charges is therefore principally due to the amphiphilic quaternary ammonium cations gathered at the liquid-vapour interface forming the TDAB/DNA clusters.

The specific arrangement we observed is consistent with a spinodal dewetting process. Such behaviour is similar to that recently observed with DNA plasmids and synthetic polyamine films incubated in aqueous media [35] that undergo nanometer-scale transformations when incubated in aqueous media. Spinodal decomposition, where spontaneous pattern formation occurs during film rupture (dewetting), appears as soon as the amplitude of fluctuations reaches the film thickness [36]. Dewetting is characterized by the formation of holes. Spinodal dewetting on silicon wafers, with both thin and thick oxide layers, was also observed by others [37] for thin liquid polystyrene (PS) films $(3.9 \mathrm{~nm})$ which are used as model polyelectrolytes. Thermal nucleation was observed by these authors for the same polymer film and surface, but with a $4.1 \mathrm{~nm}$ thick film. In this case, heterogeneous nucleation was obtained in $6.6 \mathrm{~nm}$ thick PS films. Heterogeneous nucleation only can drive the system towards dewetting from defects or impurities in the film or substrate at larger film thicknesses. Moreover, nucleation must overcome an energy barrier coming from either thermal fluctuations or a lower energy passage (pre-existing nucleation sites). Conversely, spinodal dewetting is a spontaneous self-organizing process caused by a lowering of the system free energy resulting from a spontaneous growth of initial fluctuations or defects. The observed patterns here are typical of a spinodal dewetting process (see Fig. 4). The high-density compaction of the
TDAB/DNA coating observed at the leaving edge of the bath is most probably due to the capillary forces that act at the meniscus of the bath during the vertical lift in conjunction with an elastic pulling force due to the Langmuir film break-up (build-up). The structure of the dense layer evokes orientational phases that exist in liquid crystals. The layer is compressed and oriented along a unique direction (Fig. 5). A Fourier Transform of the file presented in Fig. 5 confirms a preferential orientation of the whole layer. In fact, the particular 2D texture observed on the border of the sample is reminiscent of the structure of molecules in a smectic A liquid crystal phase. It is known that such structures are generally formed by rod-like or disklike organic molecules interacting through strongly anisotropic intermolecular forces. We guess that the Langmuir layer encountered a transition on the border of the sample which produced a 2D liquid crystal instead of the anisotropic pattern observed elsewhere on the sample due to surface strain drived spinodal decomposition.

There is evidence for condensation of the DNA plasmids. It is well known experimentally that multivalent cations can condense DNA into toroids and rods $[38,39,41]$. Condensation in the form of rod-like clusters is possible owing to both the flexibility of the DNA plasmids, solicited through their lipophilic domains engaged in hydrophobic bounds with the TDAB alkyl chains, and the sufficiently strong Coulombic interactions that dominate the entropic interactions. Within our experimental conditions, a subtle interplay between hydrophobic and electrostatic supramolecular interactions can affect the outcome of DNA condensation as suggested by Sansone et al. [40].

A water deficit due to the high degree of hydrophobization of the TDAB complexes and the electrical neutralization facilitates both condensation and attraction between plasmids. In order to make this clearer, we present in Fig. 6 AFM views of the plasmids, without surfactant complexation, immobilized on freshly cleaved muscovite mica 

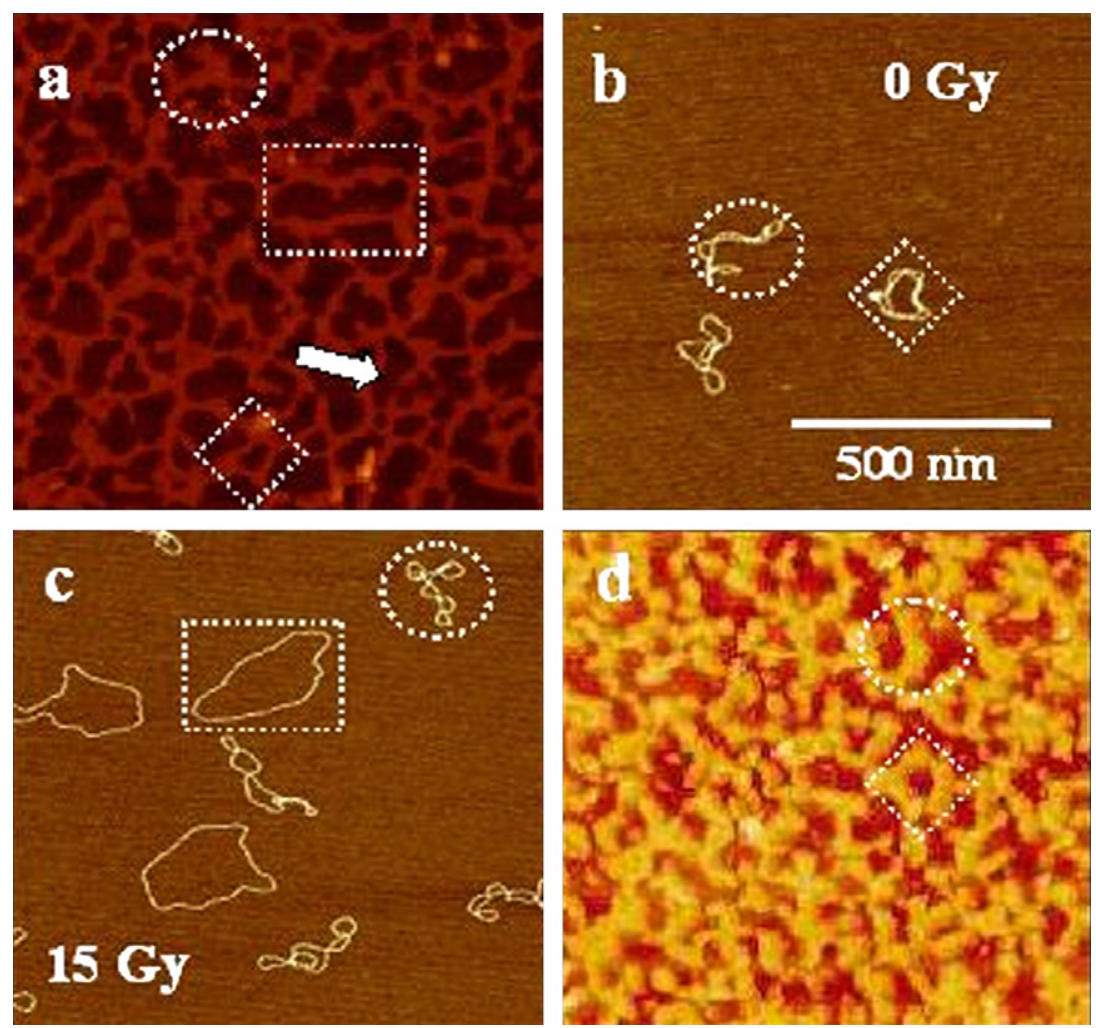

Fig. 6. (a) AFM images (tapping mode) of the characteristic TDAB/DNA networks observed on the main $\operatorname{Si}(\mathrm{B})$ surface and (d) at the vicinity of the leaving edge. The same plasmids but naked and observed on muscovite mica appear in (b) and in (c) after receiving a 15 Gray dose of X-rays. The remaining supercoiled (plectonemic) and radiation-induced circular (relaxed) forms are visible in (c). The dashed circles (supercoiled), rhombus (toroid) and rectangle (circular) are added to scale the topological forms of the plasmids. There is no evidence for a high proportion of circular conformation in the deposed TDAB/DNA complexes ( $\mathrm{a}$ and $\mathrm{d}$ ); the plasmids are in a rather condensed supercoiled form. On Figure 6a, an arrow points on a region where hemimicelisation or TDAB clusterisation occurs. Snapshots b and c were taken from a previous study [24].

after exposure to X-rays in solution. The AFM pictures obtained on mica are presented at the same magnification as those where TDAB/DNA complexes are deposed on $\mathrm{Si}(\mathrm{B})$ at high- and lower density. In Fig. 6c, after a 15 Gray X-ray dose was delivered to the DNA solution, both the supercoiled and relaxed forms are present (Fig. 6c). It appears that the circular form is quasi absent in the molecular layer (Fig. 6a and d). On the contrary, supercoiled plasmids with a high degree of condensation are the main form present in the depots.

\section{Summary and conclusion}

We have shown that the unstable TDAB/DNA complexes formed in the aqueous subphase when adsorbed on a $\mathrm{Si}(\mathrm{B})$ substrate, close to the point of phase separation, undergo a process that ressembles spinodal decomposition. This spontaneous process leads to the formation of a disordered fiber-like structure composed of a monolayer covering the surface. There is no evidence for plasmid relaxation driven by the LB step; on the contrary, dewetting facilitates the TDAB/DNA complex formation leading to DNA condensation. DNA molecules fold several times into progressively shorter toroids and rods, forming a charge-ordered structure. The cooperative forces due to both electrostatic and hydrophobic interactions lower the free energy of the system and support the formation of lace-like patterns. Interestingly, with the aid of the pulling force caused by the liquid meniscus break-up, a highly compacted and oriented monolayer is formed on the leaving edge of the sample.

The homogeneous monolayers of TDAB/DNA complexes produced cover important areas. Such patterns may be used as $2 \mathrm{D}$ templates or scaffolds for construction of nanomaterials. With their electrical conducting property, the $\mathrm{Si}(\mathrm{B})$ substrates can serve as electrodes in further experiments performed with charged particles under vacuum as well as in the gas/liquid phase. For example, studies are currently in progress in order to better understand the mechanisms of low energy electron induced desorption from DNA. There is indeed data for DNA in aqueous solution, or naked DNA immobilized on surfaces exposed to slow electrons in vacuum, but not so much is known about electron attachment de-excitation processes in well organized and complex DNA structures.

\section{Acknowledgements}

This research is financed and supported by the French Ligue de Recherche contre le Cancer (Nord 
Franche-Comté), the Canadian Institutes of Health Research and the Communauté d'Agglomération du Pays de Montbéliard.

\section{References}

[1] E. Huang, F. Zhou, L. Deng, Langmuir 16 (2000) 3272.

[2] T.-W. Cha, V. Boiadjiev, J. Lozano, H. Yang, X.-Y. Zhu, Anal. Biochem. 311 (2002) 27.

[3] R. Boukherroub, D.D.M. Wayner, J. Am. Chem. Soc. 121 (1999) 11513.

[4] S.K. Parida, S. Dash, S. Patel, B.K. Mishra, Adv. Colloid Interf. Sci. 121 (2006) 77.

[5] R.S. Dias, A.A.C.C. Pais, M.G. Miguela, B. Lindman, Colloid. Surf. A: Physicochem. Eng. Aspects 250 (2004) 115.

[6] M. Cardenas, T. Nylander, B. Lindman, Colloid. Surf. A: Physicochem. Eng. Aspects 270-271 (2005) 33.

[7] M.C. Petty, Langmuir-Blodgett Films, An Introduction, Cambridge University Press, 1996.

[8] M.N. Antipina, R.V. Gainutdinov, A.A. Rachnyanskaya, A.L. Tolstikhina, T.V. Yurova, G.B. Khomutov, Surf. Sci. 532-535 (2003) 1025.

[9] K. Ijiro, M. Shimomura, M. Tanaka, H. Nakamura, K. Hasebe, Thin Solid Film 284-285 (1996) 780.

[10] S. Dai, X. Zhang, Z. Du, H. Dang, Mater. Lett. 59 (2005) 423.

[11] J.R.C. van der Maarel, S.S. Zakharova, W. Jesse, C. Backendorf, S.U. Egelhaaf, A. Lapp, J. Phys.: Condens. Matter 15 (2003) 183.

[12] Y.T.A. Chim, J.K.W. Lam, Y. Ma, S.P. Armes, A.L. Lewis, C.J. Roberts, S. Stolnik, S.J.B. Tendler, M.C. Davies, Langmuir 21 (2005) 3591.

[13] R. Golan, L.I. Pietrasanta, W. Hsieh, H.G. Hansma, Biochemistry 38 (1999) 14069

[14] S. Hanlon, S. Brudno, T.T. Wu, B. Wolf, Biochemistry 14 (1975) 1648.

[15] M.A. Huels, B. Boudaiffa, P. Cloutier, D. Hunting, L. Sanche, J. Am. Chem. Soc. 125 (2003) 4467.

[16] D.A. Shirley, Phys. Rev. B 5 (1972) 4709.

[17] J.H. Scofield, J. Electron. Spectrosc. Relat. Phenom. 8 (1976) 129.

[18] D. Briggs, M.P. Seah, Wiley, Chichester, 1983, p. 363.

[19] C.D. Wagner, W.M. Riggs, L.E. Davis, J.F. Moulder, G.E. Muilenberg, Perkin-Elmer Corporation, Eden Prairie, MN, 1979.
[20] V.G. Babak, G.A. Vikhoreva, I.G. Lukina, Colloid. Surf. A: Physicochem. Eng. Aspects 128 (1997) 75.

[21] H.-Y. Nie, N.S. McIntyre, Langmuir 17 (2001) 432.

[22] K. Saal, V. Sammelseg, A. Lohmus, E. Kuusk, G. Raidaru, T. Rinken, et al., Biomol. Eng. 19 (2002) 195.

[23] L. Pauling, The Nature of the Chemical Bond and the Structure of Molecules and Crystals: An Introduction to Modern Structural Chemistry, Cornell University Press, 1960.

[24] S. Boichot, M. Fromm, S. Cunniffe, P. O'Neill, J.C. Labrune, A. Chambaudet, E. Delain, E. Le Cam, Radiat. Prot. Dosim. 99 (2002) 143.

[25] R. Berjoan, E. Bêche, J.A. Roger, C.H.S. Dupuy, High Temp. Chem. Process. 3 (1994) 555.

[26] R. Berjoan, E. Bêche, D. Perarnau, S. Roualdes, J. Durand, J. Phys. IV 9 (8) (1999) 1059.

[27] D.Y. Petrovykh, H. Kimura-Suda, M.J. Tarlov, L.J. Whitman, Langmuir 20 (2004) 429.

[28] Y. Maeda, T. Nakamura, K. Uchimura, T. Matsumoto, H. Tabata, T. Kawai, J. Vac. Sci. Technol. B 17 (1999) 494.

[29] J.X. Tang, N.Y. He, M.J. Tan, Q.G. He, H. Chen, Colloid. Surf. A 242 (2004) 53.

[30] D. Marton, K.J. Boyd, A.H. Al Bayati, S.S. Todorov, J.W. Rabalais, Phys. Rev. Lett. 73 (1994) 118

[31] M. Sastry, V. Ramakrishhnan, M. Pattarkine, K.J. Ganesh, Phys. Chem. B 105 (2001) 4409.

[32] M.P. Seah, Quantification of AES and XPS, in: D. Briggs, M.P. Seah (Eds.), Practical Surface Analysis, second ed., vol. 1, John Wiley \& Sons, Chichester, UK, 1990.

[33] P. Bedrossian, R.D. Meade, K. Mortensen, D.M. Chen, J.A. Golovchenko, D. Vanderbild, Phys. Rev. Lett. 63 (1989) 1257.

[34] Y. Gan, G.V. Franks, J. Phys. Chem. B 109 (2005) 12474.

[35] N.J. Fredin, J. Zhang, D.M. Lynn, Langmuir 23 (5) (2007) 2273.

[36] A. Sharma, R. Verma, Langmuir 20 (23) (2004) 10337.

[37] R. Seemann, S. Herminghaus, K. Jacobs, Phys. Rev. Lett. 86 (24) (2001) 5534.

[38] V.A. Bloomfield, Curr. Opin. Struct. Biol. 6 (1996) 334.

[39] V.A. Bloomfield, Biopolymers 31 (1991) 1471

[40] F. Sansone, M. Dudič, G. Donofrio, C. Rivetti, L. Baldini, A. Casnati, S. Cellai, R. Ungaro, J. Am. Chem. Soc. 128 (2006) 14528.

[41] Y. Fang, J. Hoh, J. Am. Chem. Soc. 120 (1998) 8903. 